\title{
HIGH INCIDENCE OF CONGENITAL HYPOTHYROIDISM IN ONE REGION OF THE REPUBLIC OF MACEDONIA
}

\author{
Anastasovska $\mathrm{V}^{1}$, Koviloska $\mathrm{R}^{2}$, Kocova $\mathrm{M}^{1, *}$
}

*Corresponding Author: Professor Dr. Mirjana Kocova, University Clinic of Pediatrics, Vodnjanska 17, 1000 Skopje, Republic of Macedonia. Tel.: +389(0)2-3123-224. Fax:+389(0)2-3111-713. E-mail: mirjanakocova@ yahoo.com

\begin{abstract}
Congenital hypothyroidism $(\mathrm{CH})$ is the most common preventable cause of mental retardation in children. Diagnosis is difficult at birth without neonatal screening. Neonatal thyroid screening was established in Prilep, Republic of Macedonia as an integral part of the nationwide screening program. To estimate the prevalence of $\mathrm{CH}$ in this region, neonatal thyroid screening was performed on 9757 newborns, during the period 2002-2011. The DELFIA method was applied to measure the thyroid-stimulating hormone (TSH) concentration in dried blood spot samples on standard filter paper taken 48 hours after birth by heel-stick. The TSH cut-off level was $10 \mathrm{mU} / \mathrm{L}$.

The neonatal thyroid screening coverage was 93.4\%. Eight newborns with $\mathrm{CH}$ were detected, with an incidence of 1:1220 live births, significantly higher compared to the nationwide results 1:2602. The TSH level was not significantly dependent on the gender of the newborn. There was a statistically significant difference between the TSH level and the timing of newborn screening sampling $(\mathrm{p}<0.05)$ and between the TSH level and the newborn birth weight $(p=0.01)$. One point ninety-two percent of newborns with TSH levels above $5 \mathrm{mU} / \mathrm{L}$ indicated an iodine sufficiency in Prilep. The incidence of CH in Prilep, which is higher when compared with that reported

\footnotetext{
${ }^{1}$ University Clinic of Pediatrics, Medical Faculty, Ss. Cyril and Methodius University, Skopje, Republic of Macedonia

${ }^{2}$ General Hospital Borka Taleski, Prilep, Republic of Macedonia
}

in surrounding countries, might be a consequence of the higher percentage of the Romany population in this region. Further analysis of this population in other regions is warranted.

Keywords: Congenital hypothyroidism $(\mathrm{CH})$; Neonatal thyroid screening; Thyroid-stimulating hormone (TSH).

\section{INTRODUCTION}

Congenital hypothyroidism $(\mathrm{CH})$ is an endocrine disorder with a major detrimental effect on the central nervous system and the development and growth, affecting 1 in 3000 to 4000 newborns [1]. Prompt treatment with thyroxine has virtually eliminated severe cognitive problems in this group of neonates [1]. The thyroid neonatal screening programs have changed the natural history of $\mathrm{CH}$. Depending on the screening needs, two screening methods are commonly used in Europe. The thyroid-stimulating hormone (TSH) is used as a general screening parameter if the screening need is prevention of severe mental retardation. The TSH screening method, as opposed to the T4 method, is less expensive and easier to perform. It is sensitive enough to distinguish between healthy and sick newborns. The TSH screening results can be used to monitor iodine insufficiency in the population. It is an important issue in many countries that are still iodine deficient. National neonatal thyroid screening was introduced in the Republic of Macedonia in 2007, as an integral part of maternal and child health care, after a pilot study of 5 years. 
Good organization and communication with the centralized screening center are favorable circumstances for the development and maintenance of a screening program in the Prilep Province, as an integral part of nationwide TSH screening program in the Republic of Macedonia.

\section{MATERIALS AND METHODS}

Neonatal screening for $\mathrm{CH}$ was performed in 9757 out of 10,446 live born neonates from the nursery at the General Hospital Borka Taleski, Prilep for the period from June 2002 to December 2011. Heelstick blood samples were taken by trained nurses, mostly 48 hours after birth and transferred to Whatman 903 filter papers (LKB Vertriebs GmbH, Vienna, Austria). They were dried and mailed daily (or every second day) to the internationally accredited central screening laboratory located at the University Clinic of Pediatrics in Skopje, Republic of Macedonia. Premature or sick full-term neonates, who usually have a prolonged stay in neonatal intensive care units, are screened between the first and second week of age. Neonates discharged from the nurseries before 48 hours of birth at the parent's request, are screened at the moment of discharge. Birth weight, gestational age at birth, gender, and timing of sampling were recorded by the nursery.

A time-resolved fluoroimmunoassay was applied to measure the TSH concentration in the dry blood spot samples using the DELFIA neonatal human thyroid-stimulating hormone (hTSH), kit manufactured by Wallac Oy, Turku, Finland. It is a solid phase, two-site fluoroimmunometric assay based on the direct sandwich technique in which two monoclonal antibodies are directed against two separate antigenic determinants on the hTSH molecule. The method was performed as per the manufacturer's instructions. Internal and external quality assurance controls were included in the TSH assay. Internal controls were made simultaneously with samples to assure the day-to-day validity of results, while external controls from Reference Institute for Bioanalytics, Bonn, Germany were included every 3 months.

The TSH values lower than $10 \mathrm{mU} / \mathrm{L}$ were considered negative for specimens taken 48 hours after birth and no further action was pursued. Results between 10 and $20 \mathrm{mU} / \mathrm{L}$ were designated borderline and a blood sample on a new filter paper (LKB
Vertiebs $\mathrm{GmbH}$ ) was requested by telephone. On this repeat sample, TSH values less than $8 \mathrm{mU} / \mathrm{L}$ were considered normal. Thyroid-stimulating hormone results greater than $20 \mathrm{mU} / \mathrm{L}$ on the initial sample were considered positive for $\mathrm{CH}$ and the newborn was referred for biochemical and clinical evaluation immediately. Neonates with confirmed hypothyroidism received therapy with levothyroxine of 10-15 $\mu \mathrm{g} / \mathrm{kg} /$ day [1].

Statistical Analysis. Data were analyzed using the Statistical Package for the Social Sciences, version 20 software (SPSS Inc., Chicago, IL, USA) and the statistical significance was set at $p<0.05$. Pearson $\chi 2$ was used for the comparison of proportions. The Mann-Whitney U test was used for the comparison of TSH mean values between different groups (according to the day of sampling, birth weight and gestational age at birth). The factorial-analysis of variance (F-ANOVA) test was used for establishing the interaction between categorical variables and the Spearman's coefficient for correlation.

\section{RESULTS}

During the period of almost 10 years, out of 10,446 live birth neonates, 9757 newborns (5603 males, 4154 females) have been screened. Ethnic distribution of the screened newborns in Prilep was as follows: $73.3 \%$ Macedonians, $17.2 \%$ Romany, 5.6\% Albanians and $3.9 \%$ other ethnicities. Compared to the state average, the Romany population is overrepresented in this region (17.2\% vs. $7.0 \%)$. According to the birth weight, neonates were devided in two groups: above $2500 \mathrm{gr}(92.9 \%$ ) and below $2500 \mathrm{gr}$ $(7.1 \%)$. The coverage of the screened newborns was $93.4 \%$ average. The TSH level was not significantly dependent on the gender of the newborn. There was a statistically significant difference between the TSH level and the timing of newborn screening sampling, before and after 48 hours of birth $(\mathrm{p}<0.05)$ (Figure 1). There was also a statistically significant difference between the TSH level and newborn birth weight, above or below $2500 \mathrm{gr}(\mathrm{p}=0.01)$ (Figure 2). A statistically significant predictor of the TSH level was only the timing of newborn screening sampling $(p<0.05)$. Spearman's correlation coefficient between TSH level, newborn birth weight and gestational age showed a significant positive correlation between birth weight and gestational age $(r=0.369, p$ 


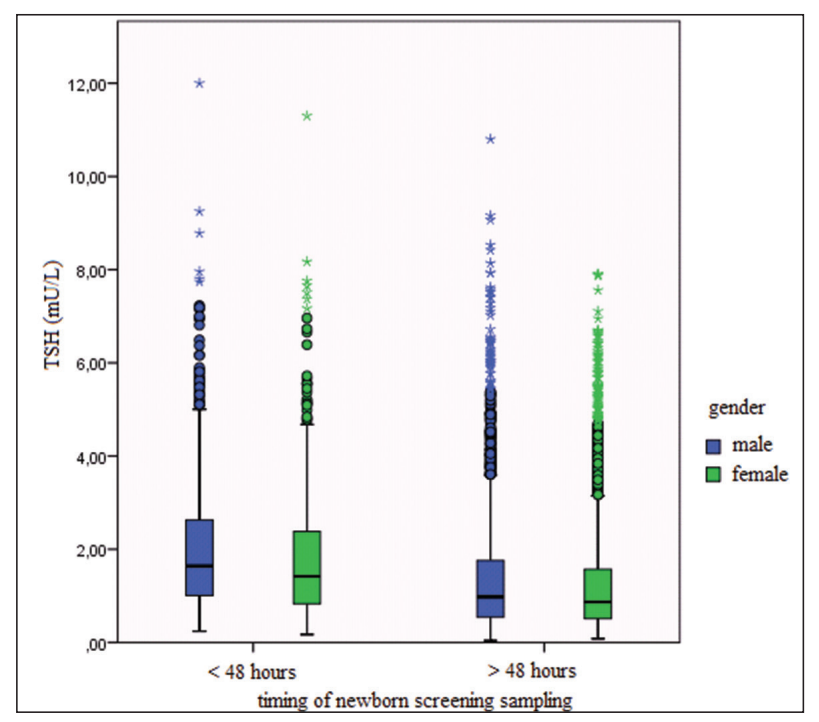

Figure 1. Statistically significant correlation between TSH level and timing of newborn screening sampling $(\mathrm{p}<0.05)$.

$<0.01$ ). During the analyzed period, $1.92 \%$ newborns had TSH levels above $5 \mathrm{mU} / \mathrm{L}$, indicating iodine sufficiency in Prilep.

The percentage of recalled neonates with borderline or abnormal initial TSH values was $0.18 \%$. Out of 18 recalled neonates, 10 (55.6\%) were categorized as healthy neonates and eight (44.4\%) were diagnosed as $\mathrm{CH}$ cases. The incidence of the disease was 1:1220 live births. Among neonates with $\mathrm{CH}$, five $(62.5 \%)$ were male and three $(37.5 \%)$ were female (male-to-female ratio 1.6:1). The prevalence of $\mathrm{CH}$ among male and female neonates was $0.89 / 1000$ (1:1121) and 0.56/1000 (1:1776), respectively. The difference was statistically significant $(\mathrm{p}<0.05)$. The distribution of TSH levels showed that seven (87.1\%) of the diagnosed $\mathrm{CH}$ neonates had initial TSH values above $20 \mathrm{mU} / \mathrm{L}$. One newborn (12.5\%) had a borderline initial TSH value, $11.3 \mathrm{mU} / \mathrm{L}$. The thyroid gland was undetectable on ultrasound in four (50.0\%) newborns with $\mathrm{CH}$, thyroid hypoplasia of one lobe was confirmed in two $(25.0 \%)$, and two $(25.0 \%)$ had a normal thyroid gland. The median age of treatment initiation with levothyroxin was 10.5 days after birth (6-12 days). Infants diagnosed with $\mathrm{CH}$ were closely followed during the first 3 years of life. They were followed-up every 2 months during the first year of life, and every 3 months during the second and third year.

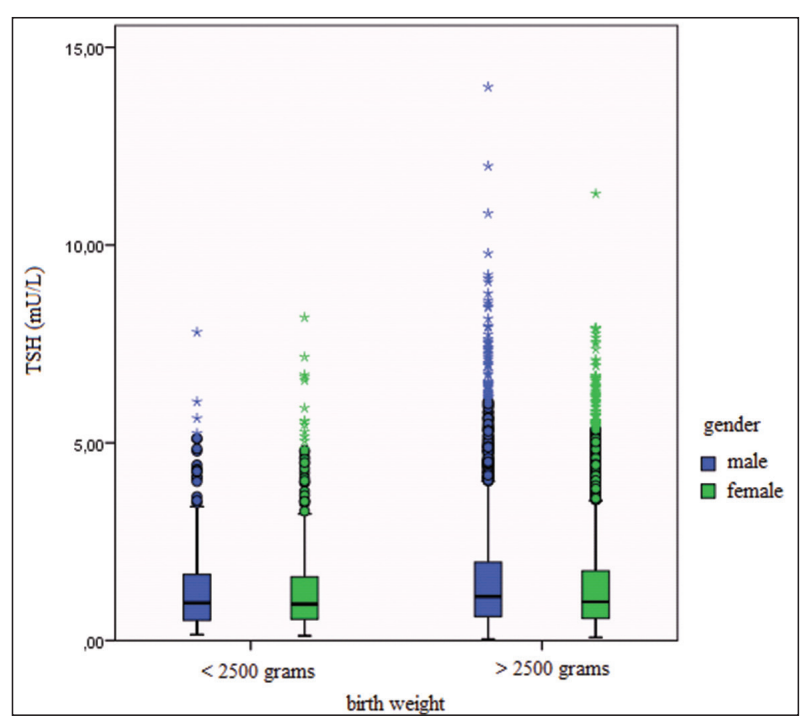

Figure 2. Statistically significant correlation between TSH level and birth weight $(\mathrm{p}=0.01)$.

\section{DISCUSSION}

The average neonatal thyroid screening coverage in Prilep was 93.4\%. The incidence of $\mathrm{CH}$ among neonates in Prilep has not been separately evaluated before. This study showed a $\mathrm{CH}$ prevalence of 1:1220 live births in the Prilep region. It is two-times higher than the state average 1:2602 [2] and three-times higher than estimated in the capital city, 1:3389 (unpublished results), for the same period. The incidence of $\mathrm{CH}$ is also significantly higher in this region compared with surrounding countries $[3,4]$ and developing countries, in general (from 1:3000 to $1: 4000)$, [5]. However, a high incidence of $\mathrm{CH}$ was reported in The Netherlands 1:1300 [6], Thailand 1:1800 [7] and Lebanon 1:1823 [8]. The different incidence rate in the Prilep Province may be related to dissimilarity between the environmental, genetic and immunologic factors. It might also be a consequence of the 2.5-fold higher percentage of the Romany population in the Prilep region (17.2\%) compaired to that in the whole state (7.0\%) [9].

Recent studies suggest that nearly all screening programs report a female preponderance, approaching 2:1 female-to-male ratio [10]. The female:male ratio varies in different studies, for example, it is 6:1 in Estonia [11] and 3:1 in Saudi Arabia [12]. In our study, this ratio was $1: 1.6$, with a male prepon- 
derance. A male preponderance of 1:1.41 was also reported in East Azerbaijan Province, Iran, probably due to the high prevalence of consanguineous marriages [13]. The difference in Prilep Province may be due to the small sample size and more probably to genetic factors.

The reported recall neonates with borderline or abnormal initial TSH values for serum TSH and T4 determination varies from 0.16 to $3.3 \%$ between different populations [14-16]. Our recall rate of $0.18 \%$ is in the lower ranges. The difference may be due to different sampling methods, different methods of performing the laboratory tests, different TSH cutoff values, and may also reflect the levels of iodine deficiency in different regions $[15,17]$.

During the study, $1.92 \%$ newborns with TSH levels above $5 \mathrm{mU} / \mathrm{L}$ were detected, indicating an iodine sufficiency in Prilep Province [18,19]. Along with urinary iodine concentrations, it has been proposed that neonatal TSH concentrations are a good indicator of the prevalence of iodine deficiency disorders in populations [20,21]. Elevated neonatal TSH concentrations may indicate insufficient supply of thyroid hormones to the developing fetal brain and is therefore the only measure that allows prediction of brain damage due to iodine deficiency [21]. The Word Health Organization (WHO) has proposed using the results of screening programs for $\mathrm{CH}$ in neonates as an additional index for the evaluation of the iodine status of the population. A frequency of neonatal TSH concentrations above $5 \mathrm{mU} / \mathrm{L}$ in less than $3.0 \%$ of the screened neonates was proposed as an indicator of iodine sufficiency. In mild iodine deficiency the frequency may be $3.0-19.9 \%$, and the frequencies of $20.0-39.9 \%$ and above $40.0 \%$ are found in countries with moderate and severe iodine deficiency, respectively [22]. Although the cutoff TSH level in neonates of $5 \mathrm{mU} / \mathrm{L}$, as set by the WHO, has been criticized [23-25], it has already been used for assessing the prevalence of iodine deficiency [26,27]. However, the Republic of Macedonia including the Prilep region has certified iodine sufficiency $[18,19]$.

\section{CONCLUSIONS}

The newborn screening program in the Prilep region is performed according to the European screening criteria. Incidence of the $\mathrm{CH}$ is significantly higher in this region compared with the state average and surrounding countries. A higher percentage of Romanies in this region might contribute to this finding. Further analysis of the causes for a high $\mathrm{CH}$ incidence in Romany population is warranted.

\section{ACKNOWLEDGMENTS}

This study was supported by Ministry of Health of the Republic of Macedonia-Screening Programs.

Declaration of Interest: The authors report no conflicts of interest. The authors alone are responsible for the content and writing of this article.

\section{REFERENCES}

1. American Academy of Pediatrics, Rose SR, Section on Endocrinology and Committee on Genetics, American Thyroid Association, Brown RS, Public Health Committee, Lawson Wilkins Pediatric Endocrine Society, Folley T, Kaplowitz PB, Kaye CL, Sundararjan S, Varma SK. Update of newborn screening and therapy for congenital hypothyroidism. Pediatrics. 2006; 117(6): 2290-2303.

2. Anastasovska $V$, Kocova $M$. Ten years experience with neonatal screening of congenital hypothyroidism in the Republic of Macedonia (abstract of the oral presentation). Proceedings of the 8th International Society for Neonatal Screening (INS) European Neonatal Screening Regional Meeting, Budapest, Hungary, November 4-6, 2012. Orvosi Hetilap, O45: 26, ISNS 2012.

3. Fellow GF, LaFranchi SH. Screening for congenital hypothyroidism: A worldwide view of strategies. Best Pract Res Clin Endocrinol Metab. 2014;28(2):175-187.

4. Samardžić M, Gligorović-Barhanović N, Popović N, Popović-Samardžić M. Newborn screening program for congenital hypothyroidism in Montenegro. Paediatrics Today. 2013; 9(2): 158-162.

5. Roberts HE, Moore CA, Fernhoff PM, Brown AL, Khoury MJ. Population study of congenital hypothyroidism and associated birth defects, Atlanta, 1979-1992. Am J Med Genet. 1997; 71(1): 29-32.

6. Loeber JG. Neonatal screening in Europe; the situation in 2004. J Inherit Metab Dis. 2007; 30(4): 430-438. 
7. Panamonta O, Tuksapun S, Kiatchoosakam P, Jirapradittha J, Kirdpon W, Loapaiboon M. Newborn screening for congenital hypothyroidism in Khon Kaen University Hospital, the first three years, a preliminary report. J Med Assoc Thai. 2003; 86(10): 932-937.

8. Daher R, Beaini M, Mahfouz R, Cortas N, Younis KA. A neonatal screening in Lebanon: Results of five years' experience. Ann Saudi Med. 2003; 23(1-2): 16-19.

9. State Statistical Office, Republic of Macedonia. Natality in the Republic of Macedonia, by municipality, 2011 (available at www.stat.gov.mk).

10. Rastogi MV, Lafranchi SH. Congenital hypothyroidism. Orphanet J Rare Dis. 2010; 5:17. doi: 10.1186/ 1772-5-17 (review).

11. Olney RS, Grosse SD, Vogt JR. Prevalence of congenital hypothyroidism - current trends and future directions: Workshop summary. Pediatrics. 2010; 125 (Suppl 2): S631-S36.

12. Al-Maghamsi MS, Al-Hawsawi ZM, Ghulam GN, Okasha AM. Screening for congenital hypothyroidism in north-west region of Saudi Arabia. Saudi Med J. 2002; 23(12): 1518-1521.

13. Zeinalzadeh AH, Talebi M. Neonatal screening for congenital hypothyroidism in East Azerbaijan, Iran: The first report. J Med Screen. 2012; 19(3): 123-126.

14. Abduljabbar MA, Afifi AM. Congenital hypothyroidism. J Pediatr Endocrinol Metab. 2012; 25(1-2): 13-29.

15. Simsek E, Karabay M, Kocabay K. Neonatal screening for congenital hypothyroidism in West Black Sea area, Turkey. J Clin Pract. 2005; 59(3): 336-341.

16. Mikelsaar RV, Zordania R, Viikmaa M, Kudrjavtseva G. Neonatal screening for congenital hypothyroidism in Estonia. J Med Screen. 1998; 5(1): 20-21.

17. Hashemipour M, Amini M, Iranpour R, Sadri GH, Javaheri N, Haghighi S, et al. Prevalence of congenital hypothyroidism in Isfahan, Iran: Results of a survey on 20,000 neonates. Horm Res. 2004; 62(1): 79-83.
18. Karanfilski B, Bogdanova V, Vaskova O, Loparska S, Miceva S, Sestakov G, et al. Correction of iodine deficiency in Macedonia. J Pediatr Endocrinol Metab. 2003; 16(7):1041-1045.

19. Dunn J. Macedonia is declared Iodine Sufficient. IDD Newslett. 2004; 20: 16-17.

20. Delange F. Neonatal screening for congenital hypothyroidism: results and perspectives. Horm Res. 1997; 48(2): 51-61.

21. Delange F. Neonatal thyroid screening as a monitoring tool for the control of iodine deficiency. Acta Pae diatr. 1999; 88(432): 21-24.

22. World Health Organization, United Nations Children's Fund, International council for the control of iodine deficiency disorders. Indicators for assessing iodine deficiency disorders and their control through salt iodization. WHO/ NUT/94.6 edition. World Health Organization, Geneva, Switzerland, 1994 (www.who.int).

23. Burus R, Mayne PD, O'Herlihy C, Smith DF, Higgins M, Staines A, et al. Can neonatal TSH screening reflect trends in population iodine intake? Thyroid. 2008; 18(8): 883-888.

24. Gruneiro-Papendieck L, Chiesa A, Mendez V, Bengolea S, Prieto L. Neonatal TSH levels as an index of iodine sufficiency: differences related to time of screening sampling and methodology. Horm Res. 2004; 62(6): 272-276.

25. Vandevijvere S, Annemans L, van Oyen H, Tafforeau J, Moreno-Reyes R. Projected reduction in healthcare costs in Belgium after optimization of iodine intake: Impact on costs related to thyroid nodular disease. Thyroid. 2010; 20(11): 1301-1306.

26. Copeland DL, Sullivan KM, Houston R, May W, Mendoza I, Salamatullah Q, et al. Comparison of neonatal thyroid-stimulating hormone levels and indicators of iodine deficiency in school children. Public Health Nutr. 2002; 5(1): 81-87.

27. Gyurjyan RH, Lugovska R, Vevere P, van der Haar F. Newborn thyrotropin screening confirms iodine deficiency in Latvia. Eur J Clin Nutr. 2006; 60(5): 688-690. 